\title{
Experimental scrutiny to induce the ramification of cutting parameters in CNC turning of AISI H21 steel employing response surface methodology
}

\author{
Rajan Jindal $^{\mathrm{a}}$ and Deepak Choudhary ${ }^{\mathrm{b}^{*}}$
}

${ }^{a}$ M.Tech. Scholar, Department of Mechanical Engineering, Yamuna Institute of Engineering \& Technology, Gadholi, Distt. Yamuna Nagar, 133103, India ${ }^{b}$ Assistant Professor, Department of Mechanical Engineering, Yamuna Institute of Engineering \& Technology, Gadholi, Distt. Yamuna Nagar, 133103, India

\section{H R O N I C L E}

Article history:

Received October 142014

Received in Revised Format

February 102015

Accepted March 272015

Available online

March 282015

Keywords:

Analysis of variance

Face centered central composite

design

Response surface methodology

Surface roughness

Turning process

\begin{abstract}
A B S T R A C T
This paper demonstrates an experimental scrutiny into turning process of hot work tool steel AISI H21 under dry machining plight. In this paper, face centered central composite design concealed by response surface methodology is practiced and analysis of variance is implemented to analyze the eloquent benefaction of machining parameters on responses. To access accommodate between the surface roughness and the MRR, an approach for concurrent optimization of multi-objective characteristics based on comprehensive desirability function is employed. The multi objective optimization concludes a spindle speed of $1599.568 \mathrm{rpm}$, feed rate of $0.262 \mathrm{~mm} / \mathrm{rev}$ and depth of cut of $2 \mathrm{~mm}$.
\end{abstract}

\section{Introduction}

In any machining operation, along with accomplishing the factual dimensions, increase metal removal rate and a good surface trait are also important. Quality influences the degree of amusement of the customers. At the same time, higher MRR is coveted by the industry to cope up with mass production product in shorter time without enduring the product trait. Higher MRR is accomplished by increasing the process parameters like depth of cut, feed and cutting speed. However, very high cutting speed craves the larger power which may eclipse the power accessible in the machine tool. Also at the same time, the cutting temperature increases with the increase in the process parameters. This influences both the tool as well as the product as it causes dimensional inaccuracies by built-up-edge formation, thermal deformation and amends the keenness of the tool and results in reverberation of the machine tool. So, excerption of pertinent process parameter plays a very vital aspect in the efficiency, effectiveness and comprehensive economy of manufacturing to accomplish the targets higher MRR and higher product trait. 
This leads optimization problem which shots to access best parametric combination for the said manufacturing process. Optimization of input variables is one of the most important characteristics in any process planning of materials to lessen the cost and time for machining. However, optimization of multi-objective problems is a great commitment of today's producers to yield the precision parts at little costs. In order to advance and optimize a surface roughness and material removal rate model, it is indispensable to perceive the current status of work in this area. A number of researchers have been focused on an appropriate method to evaluate the optimal value of the process parameters to predict the surface roughness and material removal rate. Jiang et al. (1997) examined the effect of austenite grain size on tool life \& chip deformation in turning of AISI 304L austenitic stainless steel bar and showed that inhomogeneous distribution of grain size up to a depth of $15 \mathrm{~mm}$ of the bar, resulted in tool edge breakage \& lower tool life when turning hot-forged bar as compared with quenched bars. Noordin et al. (2004) described the performance of a multi-layer WC tool using RSM when turning AISI 1045 steel. The experimental results indicated that feed was the most important parameter that influenced the tangential force $\&$ the surface roughness.

Gaitonde et al. (2008) determined the optimum amount of MQL and the most appropriate cutting speed and feed rate during turning of brass using K10 carbide tool. The optimization results indicated that MQL of $200 \mathrm{ml} / \mathrm{h}$, cutting speed of $200 \mathrm{~m} / \mathrm{min}$ and a feed rate of $0.05 \mathrm{~mm} / \mathrm{rev}$ were essential to simultaneously minimize surface roughness and specific cutting force. Aggarwal et al. (2008) presented an experimental investigation into the effect of feed rate, depth of cut, cutting speed, cutting environment and nose radius in CNC turning of AISI P-20 tool steel and revealed that cryogenic environment was the most prominent factor in minimizing power consumption followed by depth of cut and cutting speed \& also concluded that although both techniques predicted approximately similar result, RSM technique, however, seemed to an edge over the Taguchi's technique. Kaladhar et al. (2010) optimized the process parameters in turning of AISI 202 austenitic stainless steel using CVD coated cemented carbide tools. From the analysis, it was observed that the feed was the most prominent factor that affected the surface roughness followed by nose radius. Mahdavinejad and Saeedy (2011) optimized turning parameters of AISI 304 stainless steel. It was showed that cutting speed and feed rate had the main effect on the flank wear \& surface roughness respectively and the use of cutting fluid resulted in greater tool life and better surface finish.

Rodríguez et al. (2011) conducted experiments on AISI 316L, AISI 304 and AISI 420 steels during a turning process and observed that the cutting temp. increased when feed, cutting speed, depth of cut and material maximum strength increased and cutting temperature decreased with the increased of material's thermal conductivity. Asilturk et al. (2011) focused on optimizing turning parameters based on the Taguchi method to minimize surface roughness (Ra and Rz). Dry turning tests were carried out on AISI 4140 (51 HRC) with coated carbide cutting tools. Results indicated that the feed rate had the most significant effect on Ra and Rz. Sivaraman et al. (2012a) turned the multiphase (ferrite-bainitemartensite) micro alloyed steel to study the effect of machining parameters such as feed, cutting speed and depth of cut on cutting forces. The result showed that feed and depth of cut influenced more on cutting force than cutting speed. Kumar et al. (2012) examined the effect of process parameters in turning of carbon alloy steels in a CNC lathe. They used SAE8620, EN8, EN19, EN24 and EN47 carbon alloy steels for turning. It was observed that the surface roughness increased with increased feed rate and was higher at lower speeds and vice versa for all feed rates. Sivaraman et al. (2012b) carried out the machining of multiphase (ferrite-bainite-martensite) microalloyed steel in a high speed lathe to assess the machinability. The result showed that the feed rate and depth of cut influenced more on cutting force and for surface roughness the only influencing parameter was feed rate. Khamel et al. (2012) investigated the effect of process variables (depth of cut, feed rate \& cutting speed) on performance characteristics such as surface roughness, cutting forces and tool life in hard turning of AISI 52100 bearing steel with CBN tool. The results showed that feed rate and cutting speed greatly affected the tool life and surface roughness. However, depth of cut revealed maximum influenced on cutting forces. 
Barik and Mandal (2012) presented an experimental study of roughness characteristics of surface roughness generated in CNC turning of EN 31 alloy steel. It was seen that the surface roughness parameter decreased with increased in spindle speed and depth of cut but increased with increased in feed rate. Kumbhar and Waghmare (2013) used Taguchi approach to find optimum process parameters for turning hardened EN31 alloy steel. The conclusion revealed that the feed rate was the most effective parameter on surface roughness \& tool life. Ahmed et al. (2013) investigated the effect of tool overhang in the turning process on surface quality of the work piece\& tool wear. They observed that the effect of depth of cut on the surface roughness was negligible and deflection of the cutting tool increased with increased in tool overhang.

This is winded up from literature review that the Taguchi design of experiments \& response surface methodology techniques are being broadly employed in the current \& past research works on turning process. Despite the techniques RSM and Taguchi predicted near similar results, however, RSM technique sounds to an edge over the Taguchi's technique. It has also been noted that during turning, the cutting parameters which has prominent consequence on performance characteristics are speed, feed and depth of cut. Therefore, these are the parameters which are preferred to perform the experimental work on AISI H21 steel.

\section{Design of Experiments (DOE)}

The most widely employed techniques for surface roughness and material removal rate prediction in terms of machining parameters is the RSM. Therefore, face centered central composite design concealed by Response surface methodology is employed for the experiment plan in this work.

\section{Experimental Campaign}

In the pageant work, a set of experiments are run on the work piece AISI H21 hot work tool steel (as illustrated in Fig. 1) to appraise the consequence of machining parameters such as feed rate, spindle speed \& depth of cut on material removal rate and surface roughness. The cutting insert which is employed for the experiment is Taegu Tech make TT8135 grade CNMG 120412 MP TiN coated carbide insert as depicted in Fig. 2. It is clenched onto a tool holder, ISO designation DCLNR $2020 \mathrm{~K} 12$. The total length of the work piece is seized as $750 \mathrm{~mm}$ which is cut into 7 pieces in the cylindrical pattern of steel bars with diameter of $50 \mathrm{~mm}$ and length of $90 \mathrm{~mm}$ by employing Power Hacksaw. Then, 30mm length of each bar is retained in the chuck and $60 \mathrm{~mm}$ is turned in dry plight to perform 3 experiments in a single piece.

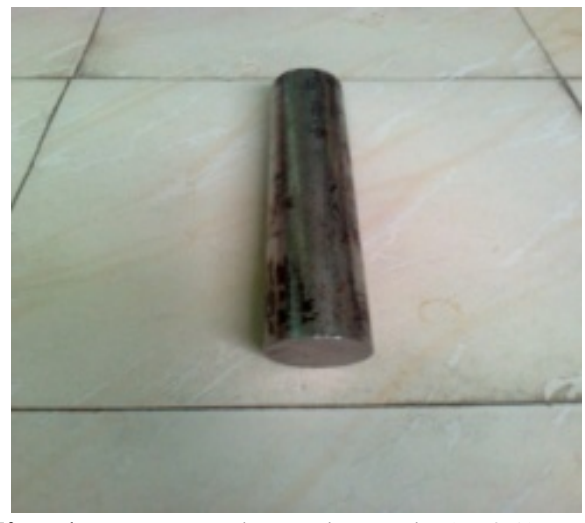

Fig. 1. Hot work tool steel (H21) rod

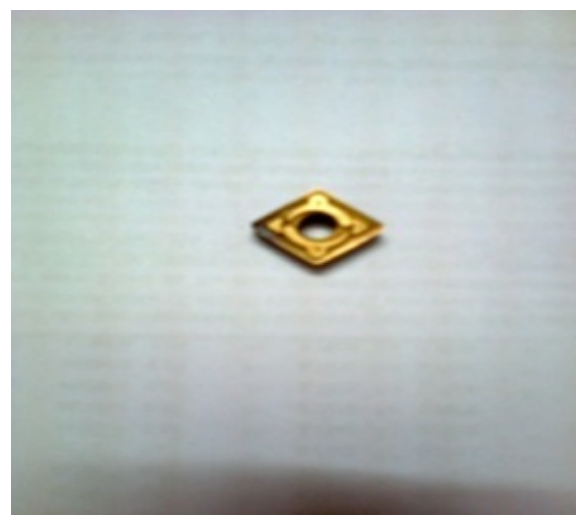

Fig. 2. Turning insert

AISI H21 steel is employed for high stressed hot work tools such as mandrels, dies and containers for metal tube and rod extrusion, screws, rivets, hot extrusion tools, tools for manufacture of hollows, die casting tools, die inserts, extrusion dies for brass, bronze and steel, hot-press dies, drawing and hotswaging dies etc. The Design Expert_ software (Stat-Ease Inc., USA) version 9.0.3.1 is employed to 
advance the experimental design matrix for RSM and to interpret the data possessed from experimentation. The range of each parameter is associated at three different levels, namely low, medium, and high based on tool manufacturer recommendation. The process parameters, their designated symbols and ranges are demonstrated in Table 1.

Table 1

Levels of Independent Control Parameters

\begin{tabular}{ccccccc}
\hline \multirow{2}{*}{ Sr. No. } & \multirow{2}{*}{ Cutting Parameters } & \multirow{2}{*}{ Symbol } & \multicolumn{3}{c}{ Level of Parameters } & \multirow{2}{*}{ Unit } \\
& & & -1 & 0 & 1 & \\
\hline 1 & Spindle speed & $\mathrm{N}$ & 400 & 1000 & 1600 & $\mathrm{RPM}$ \\
2 & Feed rate & $\mathrm{f}$ & 0.15 & 0.25 & 0.35 & $\mathrm{~mm} / \mathrm{rev}$ \\
3 & Depth of cut & $\mathrm{a}$ & 1.5 & 1.75 & 2 & $\mathrm{~mm}$ \\
\hline
\end{tabular}

\subsection{Composition testing}

Composition Testing employs the EDAX analysis which exemplifies Energy Dispersive X-ray spectroscopy. Composition of AISI H21 steel is approved on Polyvac 181 TJM Spectrometer. The chemical composition of AISI H21 hot work tool steel is exhibited in Table 2.

\section{Table 2}

Percentage of Elements in H21 hot work tool steel

\begin{tabular}{lc}
\hline Elements & \%age \\
\hline Carbon, C & 0.321 \\
Silicon, Si & 0.242 \\
Manganese, Mn & 0.335 \\
Chromium, Cr & 3.300 \\
Phosphorus, P & 0.023 \\
Sulphur, S & 0.020 \\
Vanadium, V & 0.393 \\
Tungsten, W & 9.120 \\
Molybdenum, Mo & 0.350 \\
Cobalt, Co & 0.150 \\
Tin, Sn & 0.015 \\
Iron, Fe & 85.630 \\
\hline
\end{tabular}

\subsection{Properties of the material}

The various physical and mechanical properties of AISI H21steel are shown in Tables 3 and Table 4.

\section{Table 3}

Physical Properties

Physical Properties

Metric

\begin{tabular}{ll} 
Specific gravity g/cc & 8.19 \\
Density $\left(\mathrm{kg} / \mathrm{m}^{3}\right)$ & $8.28 \times 1000$ \\
\hline
\end{tabular}

\section{Table 4}

Mechanical Properties

\begin{tabular}{|c|c|c|}
\hline Mechanical Properties & Metric & Conditions \\
\hline Poisson's ratio & $0.27-0.30$ & 25 \\
\hline Elastic modulus (GPa) & $190-210$ & 25 \\
\hline
\end{tabular}




\subsection{Equipment employed}

A HMT CNC turning center STALLION 100HS is employed for experimentation as presented in Fig. 3. The lathe equipped with variable spindle speed from $100 \mathrm{rpm}$ to $3000 \mathrm{rpm}$, and a $5.5 \mathrm{~kW}$ motor drive is employed for the tests.

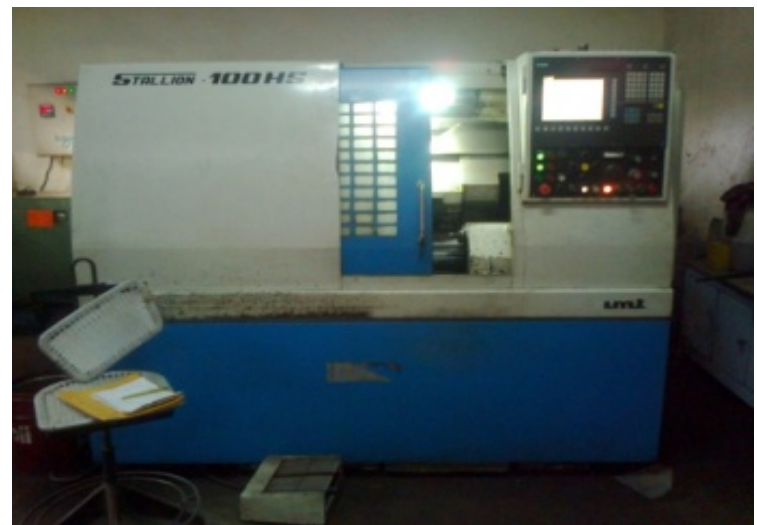

Fig. 3. A HMT CNC turning center STALLION $100 \mathrm{HS}$

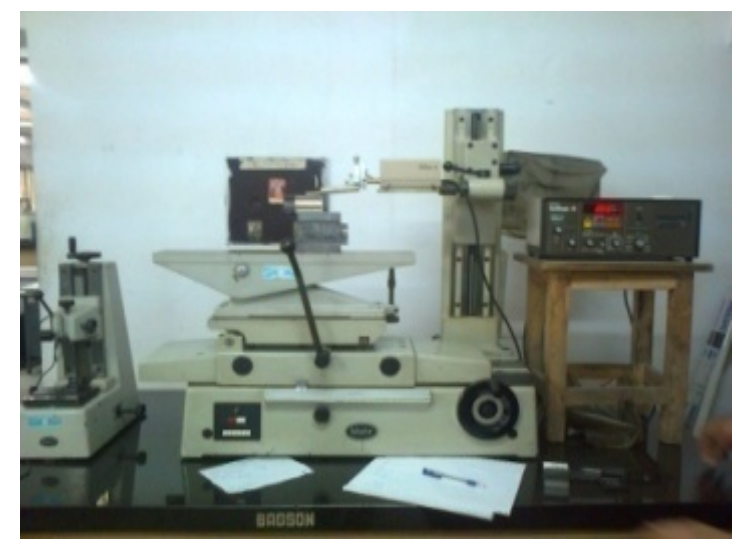

Fig. 4. Mitutoyo surftest-4 surface roughness tester

\subsection{Roughness measurement}

Surface roughness is consistent employing stylus type Mitutoyo surftest-4 on a turned length of $20 \mathrm{~mm}$ as exposed in Fig. 4. Three measurements are run along the length of cut on each work piece and the average Ra value is listed.

\section{Table 5}

Experimental Design matrix with uncoded values and observed responses

\begin{tabular}{|c|c|c|c|c|c|c|c|c|}
\hline $\begin{array}{c}\text { Stadard } \\
\text { order }\end{array}$ & $\begin{array}{l}\text { Spindle } \\
\text { speed, } \\
\text { r.p.m. }\end{array}$ & $\begin{array}{c}\text { Feed rate } \\
\mathrm{mm} / \mathrm{rev}\end{array}$ & $\begin{array}{l}\text { Depth of } \\
\text { cut, mm }\end{array}$ & $\begin{array}{c}\text { Material } \\
\text { removal rate, } \\
\mathrm{mm}^{3} / \mathrm{sec}\end{array}$ & Ra 1 & Ra 2 & Ra 3 & $\begin{array}{c}\text { Mean surface } \\
\text { roughness, Ra in } \\
\mu \mathrm{m}\end{array}$ \\
\hline 1 & 400 & 0.15 & 1.50 & 226.08 & 2.63 & 2.18 & 2.75 & 2.520 \\
\hline 2 & 1600 & 0.15 & 1.50 & 904.32 & 2.29 & 2.00 & 2.10 & 2.130 \\
\hline 3 & 400 & 0.35 & 1.50 & 527.52 & 2.83 & 3.15 & 2.49 & 2.823 \\
\hline 4 & 1600 & 0.35 & 1.50 & 2110.08 & 3.02 & 3.12 & 3.02 & 3.053 \\
\hline 5 & 400 & 0.15 & 2.00 & 301.44 & 2.75 & 2.78 & 2.77 & 2.767 \\
\hline 6 & 1600 & 0.15 & 2.00 & 1205.76 & 2.47 & 2.18 & 2.36 & 2.337 \\
\hline 7 & 400 & 0.35 & 2.00 & 703.36 & 2.81 & 3.11 & 3.35 & 3.090 \\
\hline 8 & 1600 & 0.35 & 2.00 & 2813.44 & 2.86 & 3.00 & 2.82 & 2.893 \\
\hline 9 & 400 & 0.25 & 1.75 & 439.6 & 3.04 & 3.00 & 2.47 & 2.837 \\
\hline 10 & 1600 & 0.25 & 1.75 & 1758.4 & 2.05 & 1.95 & 2.30 & 2.100 \\
\hline 11 & 1000 & 0.15 & 1.75 & 659.4 & 2.59 & 2.98 & 2.55 & 2.707 \\
\hline 12 & 1000 & 0.35 & 1.75 & 1538.6 & 2.94 & 2.86 & 2.77 & 2.857 \\
\hline 13 & 1000 & 0.25 & 1.50 & 942.00 & 2.20 & 2.67 & 2.64 & 2.503 \\
\hline 14 & 1000 & 0.25 & 2.00 & 1256.00 & 2.50 & 3.16 & 2.76 & 2.807 \\
\hline 15 & 1000 & 0.25 & 1.75 & 1099.00 & 2.06 & 2.48 & 3.20 & 2.580 \\
\hline 16 & 1000 & 0.25 & 1.75 & 1099.00 & 2.27 & 3.42 & 2.80 & 2.830 \\
\hline 17 & 1000 & 0.25 & 1.75 & 1099.00 & 2.02 & 2.64 & 2.81 & 2.490 \\
\hline 18 & 1000 & 0.25 & 1.75 & 1099.00 & 2.53 & 2.81 & 3.15 & 2.830 \\
\hline 19 & 1000 & 0.25 & 1.75 & 1099.00 & 2.72 & 2.7 & 2.40 & 2.607 \\
\hline 20 & 1000 & 0.25 & 1.75 & 1099.00 & 2.74 & 2.57 & 2.42 & 2.577 \\
\hline
\end{tabular}


In Table 5 material removal rate is computed by the product of cutting speed (Vc), feed rate (f) and depth of cut (a) and revealed in $\mathrm{mm}^{3} / \mathrm{sec}$ as:

$$
\operatorname{MRR}=1000 \times \mathrm{Vc} \times \mathrm{f} \times \mathrm{a}\left(\mathrm{mm}^{3} / \mathrm{min}\right)
$$

And cutting speed is calculated as,

$$
V c=\frac{\pi \times D \times N}{1000}
$$

Where $\mathrm{Vc}=$ cutting speed in $\mathrm{m} / \mathrm{min} ; \mathrm{D}=$ Diameter of work piece in $\mathrm{mm} ; \mathrm{N}=$ Spindle Speed in r.p.m.

\section{Results and Discussion}

\subsection{Development of empirical models}

Employing the experimental data, analytical model for surface roughness and material removal rate is developed using multiple linear regression (MLR) analysis. The dependent variable surface roughness and MRR is conceived as a linear consolidation of the independent variables namely feed rate, spindle speed \& depth of cut.

Since, there are large numbers of variables governing the process, so empirical models are imperative to represent the process. However, these models are advanced using only the momentous factors.

\subsection{Final equation in terms of actual factors for MRR and $R a$}

$$
\begin{aligned}
& M R R=1099-1.099 N-4396 f-628 a+4.396 N f+0.628 N a+2512 f a \\
& R a=2.362-\left(2.550 \times 10^{-4} N\right)+2.240 f
\end{aligned}
$$

These equations are in terms of actual factors which can be employed to build predictions about the responses MRR and surface roughness $(\mathrm{Ra})$ for given levels of each factor.

\subsection{Analysis of variance (ANOVA)}

In order to develop empirical models, statistical analysis of the experimental results is indispensable by employing analysis of variance. ANOVA is a computational technique that empowers the estimation of the relative contributions of each of the control factors to the comprehensive deliberated response.

\section{Table 6}

Analysis of variance table for MRR after backward elimination

\begin{tabular}{lccccccc}
\hline Source & $\begin{array}{c}\text { Sum of } \\
\text { Squares }\end{array}$ & df & $\begin{array}{c}\text { Mean } \\
\text { Square }\end{array}$ & F Value & $\begin{array}{c}\text { p-value } \\
\text { Prob }>\text { F }\end{array}$ & $\begin{array}{c}\text { Contribution } \\
\text { \%age }\end{array}$ \\
\hline Model & $7.19 \times 10^{6}$ & 6 & $1.20 \times 10^{6}$ & 1370.81 & $<0.0001$ & & significant \\
A-Spindle speed & $4.35 \times 10^{6}$ & 1 & $4.35 \times 10^{6}$ & 4976.56 & $<0.0001$ & 60.4056 & significant \\
B-Feed rate & $1.93 \times 10^{6}$ & 1 & $1.93 \times 10^{6}$ & 2211.81 & $<0.0001$ & 26.8407 & significant \\
C-Depth of cut & $2.47 \times 10^{5}$ & 1 & $2.47 \times 10^{5}$ & 282.12 & $<0.0001$ & 3.4245 & significant \\
AB & $5.57 \times 10^{5}$ & 1 & $5.57 \times 10^{5}$ & 637 & $<0.0001$ & 7.7327 & significant \\
AC & 70989.12 & 1 & 70989.12 & 81.25 & $<0.0001$ & 0.986 & significant \\
BC & 31550.72 & 1 & 31550.72 & 36.11 & $<0.0001$ & 0.438 & significant \\
Residual & 11358.26 & 13 & 873.71 & $\ldots$. & $\ldots$ & 0.157 & \\
Lack of fit & 11358.26 & 8 & 1419.78 & $\ldots \ldots$ & $\ldots$. & & \\
Pure error & 0 & 5 & 0 & $\ldots$. & $\ldots$. & & \\
Cor Total & $7.20 \times 10^{6}$ & 19 & $\ldots$ & $\ldots$ & $\ldots$. & & \\
\hline
\end{tabular}


Table 6 reveals that model is significant and there is only a $0.01 \%$ incidental that an F-value of model can be large due to noise. If the p- value probability $>\mathrm{F}$ is less than 0.05 then, it depicts model terms are significant. In this case A (spindle speed), B (feed rate), C (depth of cut), AB, AC, BC are significant model terms.

\subsubsection{ANOVA for response surface linear model i.e. for $\mathrm{Ra}$}

Result of ANOVA for the Ra model is delineated in Table 7. It represents that model is significant and there is only a $0.19 \%$ contingent that an F-value of model can be large due to noise. In this case A (spindle speed) and B (feed rate) are significant model terms. The values $>0.100$ manifests that the model terms are not significant.

Table 7

Analysis of variance table for Ra

\begin{tabular}{ccccccc}
\hline Source & $\begin{array}{c}\text { Sum of } \\
\text { Squares }\end{array}$ & df & Mean Square & F Value & $\begin{array}{c}\text { P-value } \\
\text { Prob }>\text { F }\end{array}$ \\
\hline Model & 0.81 & 3 & 0.27 & 7.82 & 0.0019 & significant \\
A-Spindle speed & 0.23 & 1 & 0.23 & 6.75 & 0.0194 & significant \\
B-Feed Rate & 0.5 & 1 & 0.5 & 14.47 & 0.0016 & significant \\
C-Depth of cut & 0.077 & 1 & 0.077 & 2.23 & 0.1545 & not significant \\
Residual & 0.55 & 16 & 0.035 & $\ldots$. & $\ldots$ & $\ldots$. \\
Lack of fit & 0.45 & 11 & 0.041 & 2.02 & 0.2255 & not significant \\
Pure error & 0.1 & 5 & 0.02 & $\ldots$. & $\ldots$. & $\ldots$ \\
Cor Total & 1.37 & 19 & $\ldots$ & $\ldots$. & $\ldots$. & $\ldots$ \\
\hline
\end{tabular}

\subsubsection{ANOVA for response surface reduced linear model i.e. for $\mathrm{Ra}$}

The ANOVA table for the reduced linear model for Ra is laid out in Table 1.8. The F-value of lack of fit i.e. 2.17 implies that lack of fit is insignificant relative to the pure error. There is a $20.16 \%$ incidental that a lack of fit, F-value can be large due to noise.

\section{Table 8}

Analysis of variance table for Ra after backward elimination

\begin{tabular}{lccccccc}
\hline \multicolumn{1}{c}{ Source } & $\begin{array}{c}\text { Sum of } \\
\text { Squares }\end{array}$ & df & $\begin{array}{c}\text { Mean } \\
\text { Square }\end{array}$ & F Value & $\begin{array}{c}\text { p-value } \\
\text { Prob> F }\end{array}$ & $\begin{array}{c}\text { Contribution } \\
\text { \%age }\end{array}$ & \\
\hline Model & 0.74 & 2 & 0.37 & 9.89 & 0.0014 & & significant \\
A-Spindle speed & 0.23 & 1 & 0.23 & 6.3 & 0.0225 & 16.788 & significant \\
B-Feed rate & 0.5 & 1 & 0.5 & 13.49 & 0.0019 & 36.496 & significant \\
Residual & 0.63 & 17 & 0.037 & $\ldots$. & $\ldots$. & & $\ldots$. \\
Lack of fit & 0.53 & 12 & 0.044 & 2.17 & 0.2016 & & not significant \\
Pure error & 0.1 & 5 & 0.02 & $\ldots$ & $\ldots$. & & $\ldots$. \\
Cor Total & 1.37 & 19 & $\ldots .$. & $\ldots$ & $\ldots$ & & $\ldots$. \\
\hline
\end{tabular}

Table 1.9 represents that the value of predicted $\mathrm{R}^{2}$ i.e. 0.9791 is in reasonable agreement with the value of adjusted $\mathrm{R}^{2}$ i.e. 0.9977 for MRR since the difference is less than 0.2 . The value of adequate precision $>4$ is desirable which manifests an adequate signal and summons that model can be employed to navigate the design space.

\section{Table 9}

Various $\mathrm{R}^{2}$ statistics for MRR

\begin{tabular}{lclc}
\hline Standard deviation & 29.56 & $\mathrm{R}^{2}$ (Coefficient of determination) & 0.9984 \\
Mean & 1099 & Adjusted R $^{2}$ & 0.9977 \\
& 2.69 & Predicted R & 0.9791 \\
& $1.50 \times 10^{5}$ & Adequate Precision & 143.649 \\
\hline
\end{tabular}


Table 10 illustrates that the value of predicted $\mathrm{R}^{2}$ is in reasonable agreement with the value of adjusted $\mathrm{R}^{2}$ for the Ra.

Table 10

Various $\mathrm{R}^{2}$ statistics for Ra

\begin{tabular}{llll}
\hline Standard deviation & 0.19 & $\mathrm{R}^{2}$ & 0.5379 \\
Mean & 2.67 & Adjusted R $^{2}$ & 0.4835 \\
& 7.23 & Predicted R & 0.3229 \\
& 0.93 & Adequate Precision & 10.096 \\
\hline
\end{tabular}

\subsection{Influence of cutting parameters on MRR \& $R a$}

The influence of process parameters on output responses i.e. MRR and Ra are presented in Figures below.

\subsubsection{Residuals vs. Run plot}

The plots below illustrate a random pattern of residuals on both sides of 0.00 and do not expose any recognizable patterns. Thus, it implies that there is nothing awesome about the residuals in Fig. 5 and Fig. 6.

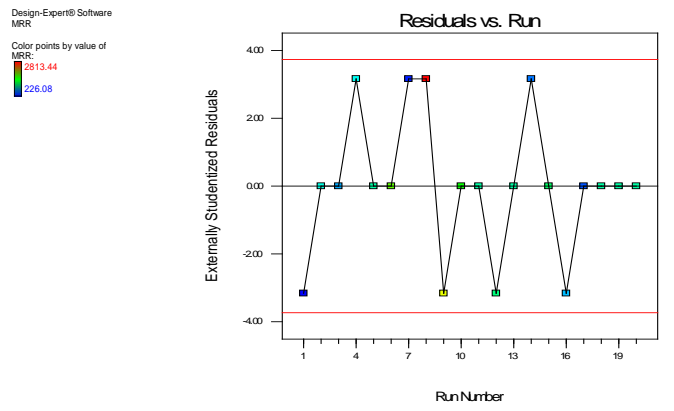

Fig. 5. Residuals vs Run plot for MRR

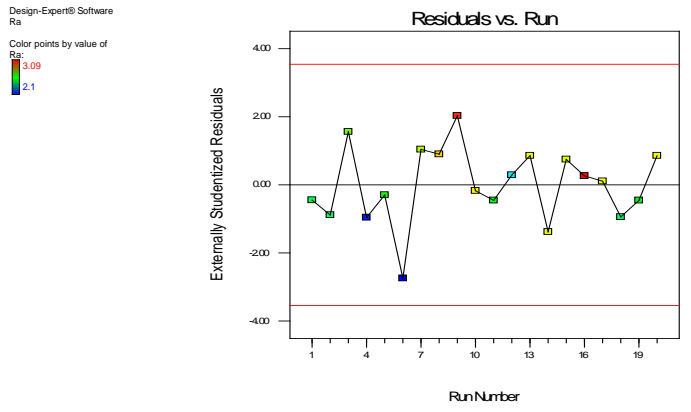

Fig. 6. Residuals vs Run plot for Ra

\subsubsection{Interaction plot}

An interaction occurs when the response is disparate, anticipating on the settings of two factors. When the lines are parallel, interaction influences are zero. The more distinctive the slopes, the more influence the interaction repercussion on the results. The interaction plots for MRR vs spindle speed and feed rate delineate that MRR increases with increase in spindle speed, however, the influence of spindle speed is large when feed rate is at $0.35 \mathrm{~mm} / \mathrm{rev}$ as shown in Fig. 7. Similarly, the influence of feed rate on MRR is more, when depth of cut is $2 \mathrm{~mm}$ as demonstrate in Fig. 8. Thus, the maximum value of MRR is achieved at the highest range of the input parameters in all the interaction plots.

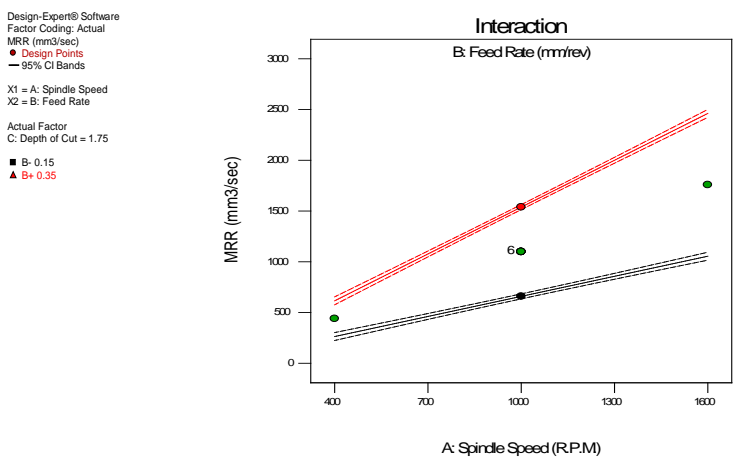

Fig. 7. Interaction plot for MRR vs Spindle speed and feed rate
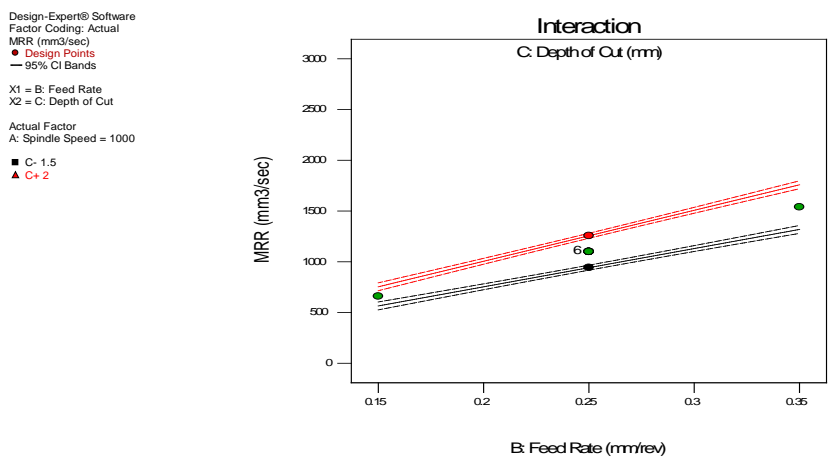

Fig. 8. Interaction plot for MRR vs Feed rate and depth of cut 
Fig. 9 reveals interaction plot for surface roughness vs feed rate and spindle speed. This plot represents that $\mathrm{Ra}$ is minimum when spindle speed is at 1600 r.p.m.

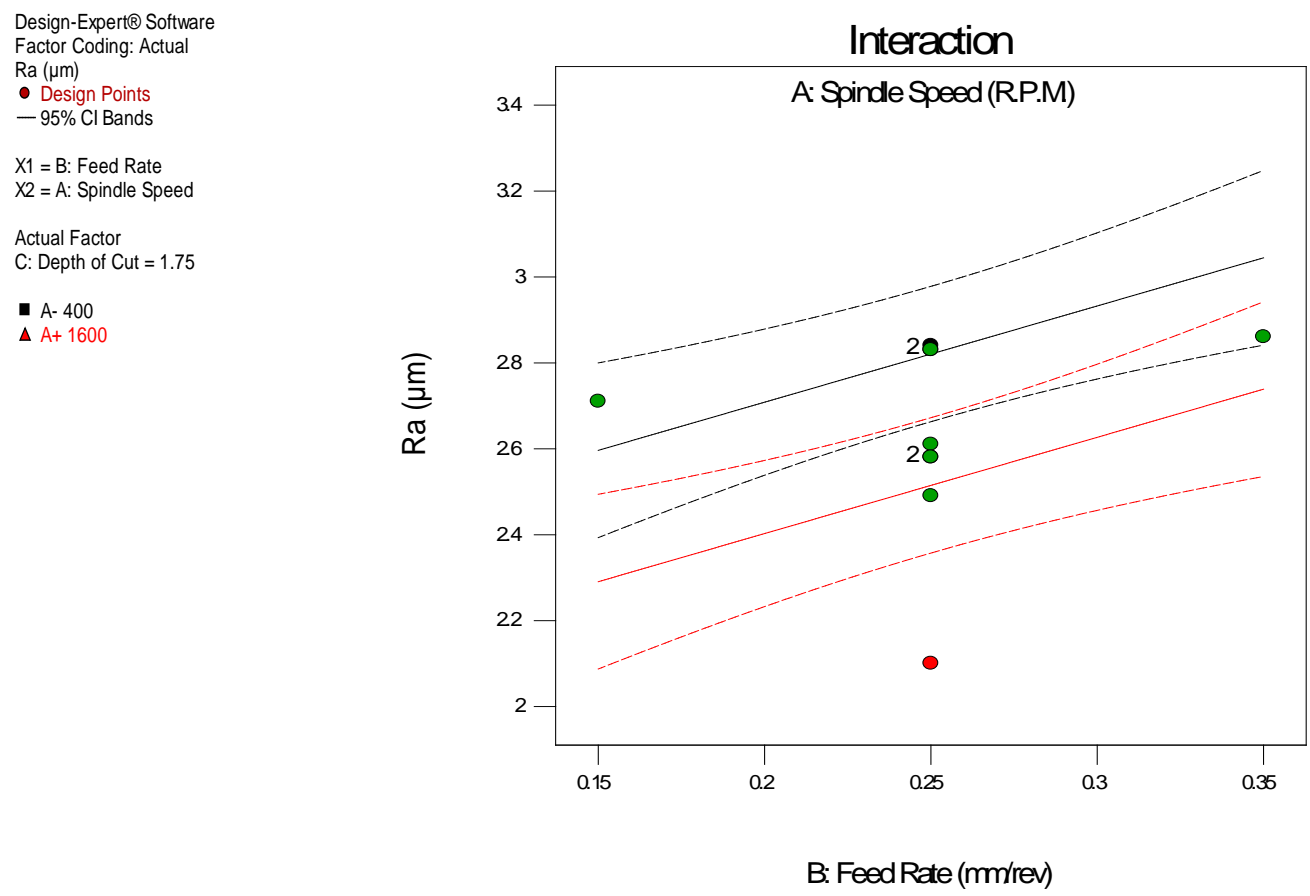

Fig. 9. Interaction plot for Ra vs Feed rate and spindle speed

\subsubsection{3-D surface plots}

It is contemplated that increase in spindle speed and feed rate lean to increase the MRR as exhibit in Fig. 10. It is noted from Fig. 11 that the increase in depth of cut causes the MRR marginally increase. Thus, increasing the feed rate, spindle speed \& depth of cut expedite an increase in the extent of material removal rate.

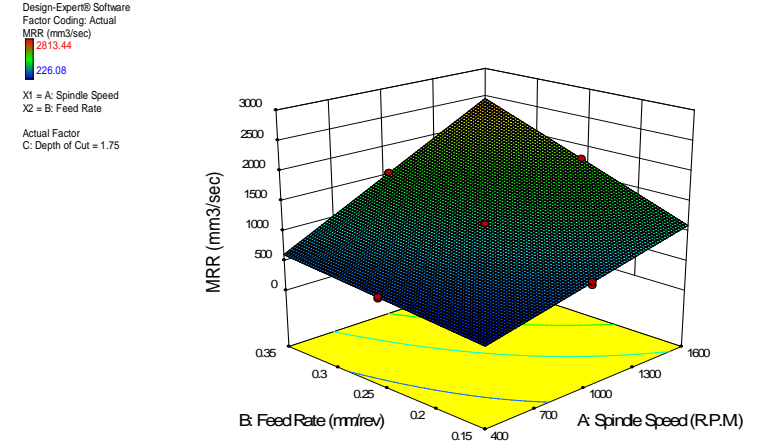

Fig. 10. Influence of Feed rate \& Spindle speed on MRR

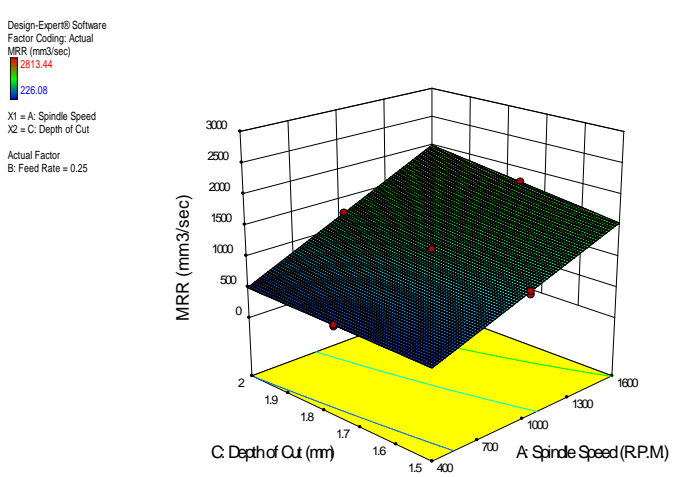

Fig. 11. Influence of Depth of cut \& Spindle speed on MRR

The consequence of process parameters on output response, surface roughness is shown in Fig. 12. From this Fig, it is ascertained that as the feed rate increases, Ra also increases but as the spindle speed increases then surface roughness decreases. 


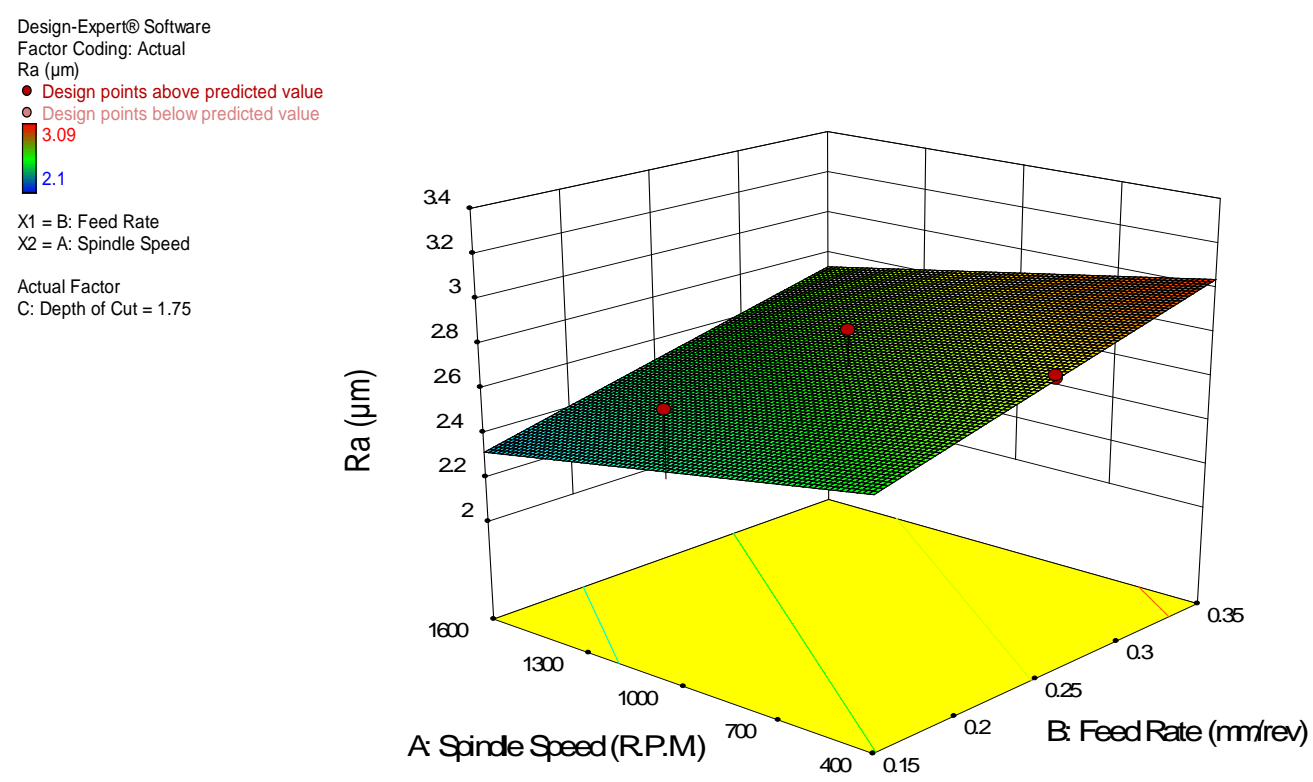

Fig. 12. Influence of Spindle speed \& Feed rate on Ra

\section{Optimization of the problem}

Desirability is quietly a mathematical method to access the optimum. By default, the input factors are set "in range", thus preventing extrapolation as laid out in Table 11.

Table 11

Constraints for combined MRR and Ra

\begin{tabular}{|c|c|c|c|c|c|c|}
\hline Name & Goal & Lower Limit & Upper Limit & $\begin{array}{l}\text { Lower } \\
\text { Weight }\end{array}$ & $\begin{array}{c}\text { Upper } \\
\text { Weight }\end{array}$ & Importance \\
\hline A: Spindle speed & is in range & 400 & 1600 & 1 & 1 & 3 \\
\hline B: Feed rate & is in range & 0.15 & 0.35 & 1 & 1 & 3 \\
\hline C: Depth of cut & is in range & 1.5 & 2 & 1 & 1 & 3 \\
\hline MRR & maximize & 226.08 & 2813.44 & 1 & 1 & 3 \\
\hline $\mathrm{Ra}$ & minimize & 2.1 & 3.09 & 1 & 1 & 3 \\
\hline
\end{tabular}

Three solutions are attained. They are presented in Table 12. Solution 1, which is having maximum value of desirability i.e. 0.634 , is tabbed. The optimum values of spindle speed, feed rate and depth of cut to maximize the MRR $\left(2097.3 \mathrm{~mm}^{3} / \mathrm{sec}\right) \&$ minimize the Ra $(2.54 \mu \mathrm{m})$ are 1599.568 r.p.m., $0.262 \mathrm{~mm} / \mathrm{rev}$ and $2 \mathrm{~mm}$ respectively.

\section{Table 12}

Optimization solutions for combined MRR and Ra

\begin{tabular}{cccccccc}
\hline Number & Spindle speed & Feed rate & Depth of Cut & MRR & Ra & \multicolumn{2}{c}{ Desirability } \\
\hline 1 & 1599.568 & 0.262 & 2 & 2097.3 & 2.54 & 0.634 & Selected \\
2 & 1600 & 0.272 & 2 & 2176.9 & 2.563 & 0.633 & $\ldots \ldots$ \\
3 & 1600 & 0.222 & 2 & 1796.2 & 2.452 & 0.625 & $\ldots .$. \\
\hline
\end{tabular}

\subsection{Numerical optimization Ramps}

Ramps view reveals the desirability for each factor and each response. The ramp function graph for overall desirability for MRR and Ra is illustrated in Fig. 13. In this figure, red mark on curves of spindle speed, feed rate and depth of cut are delineating the optimum values. The corresponding optimum value 
of response i.e. MRR and Ra is also exposed by blue dot on curves of these responses. Fig. 13 also depicts the individual desirability value of these multi-objective characteristics.

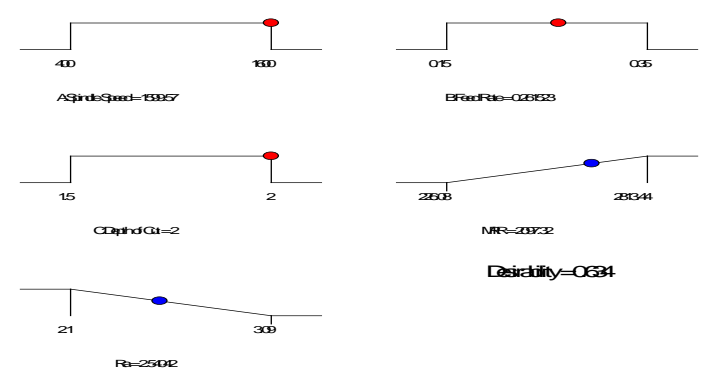

Fig. 13. Ramp function plot for combined for MRR \& Ra

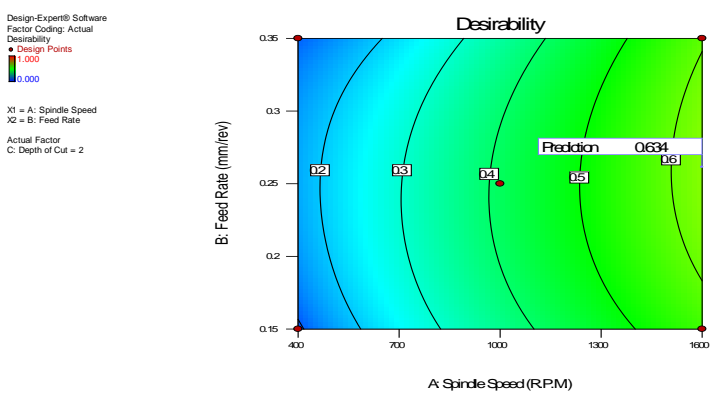

Fig. 14. Contour plot at maximum desirability value for combined MRR \& Ra

\subsection{Contour plot at maximum desirability value of responses}

Contour graph (Fig. 14) at maximum desirability value (0.634) presents optimum values of spindle speed and feed rate. This plot manifests that increase in spindle speed and feed rate result in increase in desirability value of MRR \& Ra.

\section{Conclusion}

It can be winded up from above analysis that response surface method can be successfully employed to induce optimal values of cutting parameters for multi-objective problem. Surface roughness \& MRR parameters greatly rely on work piece material. Material removal rate increases with the increase in feed rate, spindle speed \& depth of cut. The ramification of the depth of cut on the surface roughness is negligible. Surface roughness parameter decreases with increase in spindle speed but increases with increase in feed rate. The values of cutting parameters: spindle speed of $1599.568 \mathrm{rpm}$, feed rate of 0.262 $\mathrm{mm} / \mathrm{rev}$ and depth of cut of $2 \mathrm{~mm}$ are foreseen to counter with a minimum surface roughness and maximum MRR.

\section{Acknowledgement}

We would like to acknowledge Research \& Development Centre for Bicycle \& Sewing Machine, Ludhiana, India for providing CNC machining facility and the surface roughness tester to carry out this experimental work.

\section{References}

Aggarwal, A., Singh, H., Kumar, P., \& Singh, M. (2008). Optimizing power consumption for CNC turned parts using response surface methodology and Taguchi's technique-a comparative analysis. Journal of Materials Processing Technology, 200(1), 373-384.

Ahmed, G. S., Ahmed, H., \& Samad, S. S. (2013). Experimental investigation of effect of tool length on surface roughness during turning operation and its optimization. IOSR Journal of Mechanical and Civil Engineering, 7(2), 73-80.

Asiltürk, I., \& Akkuş, H. (2011). Determining the effect of cutting parameters on surface roughness in hard turning using the Taguchi method. Measurement, 44(9), 1697-1704.

Barik, C. R., \& Mandel, N. K. (2010). Parametric effect and optimization of surface roughness of EN 31 in CNC dry turning. International Journal of Lean Thinking, 3(2), 1-13. 
Gaitonde, V. N., Karnik, S. R., \& Davim, J. P. (2008). Selection of optimal MQL and cutting conditions for enhancing machinability in turning of brass. Journal of Materials Processing Technology, 204(1), 459-464.

Jiang, L., Roos, Å., \& Liu, P. (1997). The influence of austenite grain size and its distribution on chip deformation and tool life during machining of AISI 304L.Metallurgical and Materials Transactions A, 28(11), 2415-2422.

Kaladhar, M., Subbaiah, K. V., Rao, C. S., \& Rao, K. N. (2010). Optimization of process parameters in turning of AISI202 austenitic stainless steel. ARPN Journal of Engineering and Applied Sciences, 5(9), 79-87.

Khamel, S., Ouelaa, N., \& Bouacha, K. (2012). Analysis and prediction of tool wear, surface roughness and cutting forces in hard turning with CBN tool. Journal of mechanical science and technology, 26(11), 3605-3616.

Kumar, N. S., Shetty, A., Shetty, A., Ananth, K., \& Shetty, H. (2012). Effect of spindle speed and feed rate on surface roughness of Carbon Steels in CNC turning. Procedia Engineering, 38, 691-697.

Kumbhar, Y. B., \& Waghmare, C. A. (2013). Tool Life And Surface Roughness Optimization Of PVD TiAlN/TiN Multilayer Coated Carbide Inserts In Semi Hard Turning Of Hardened EN31 Alloy Steel Under Dry Cutting Conditions. International Journal of Advanced Engineering Resources Studies, 2(4), 22-27.

Mahdavinejad, R. A., \& Saeedy, S. (2011). Investigation of the influential parameters of machining of AISI 304 stainless steel. Sadhana, 36(6), 963-970.

Noordin, M. Y., Venkatesh, V. C., Sharif, S., Elting, S., \& Abdullah, A. (2004). Application of response surface methodology in describing the performance of coated carbide tools when turning AISI 1045 steel. Journal of Materials Processing Technology, 145(1), 46-58.

Rodríguez, J., Muñoz-Escalona, P., \& Cassier, Z. (2011). Influence of cutting parameters and material properties on cutting temperature when turning stainless steel. Revista de la Facultad de Ingeniería Universidad Central de Venezuela, 26(1), 71-80.

Sivaraman, V., Sankaran, S., \& Vijayaraghavan, L. (2012a). The Effect of Cutting Parameters on Cutting Force During Turning Multiphase Microalloyed Steel. Procedia CIRP, 4, 157-160.

Sivaraman, V., Sankaran, S., \& Vijayaraghavan, L. (2012b). Machinability of multiphase microalloyed steel. Procedia CIRP, 2, 55-59. 